\title{
Ocular Biometry and Corneal Astigmatism in Patients Undergoing Cataract Surgery in Bheri Zone of Nepal
}

\author{
Thapa $\mathrm{BB}^{1}$, Dhakal $\mathrm{Y}^{2}$, Verma JK $\mathrm{K}^{3}$, Manandhar $\mathrm{P}^{4}$
}

\begin{abstract}
Introduction: Accurate measurement of ocular axial length, keratometry and anterior chamber depth before cataract surgery is crucial for calculating the power of intraocular lens (IOL) to be implanted. Corneal astigmatism is one of the major thefts to have best postoperative unaided visual acuity. Thus, knowing it preoperatively and taking appropriate intervention during surgery provides best postoperative visual outcome. But there are no studies on corneal astigmatism and biometric parameters in the population of Bheri Zone. MATERIAL AND METHOD: The medical records of the patients who had undergone cataract surgery between January 2017 and November 2017 at Nepalgunj medical college were retrospectively reviewed and analyzed. Patient's demographic parameter, keratometric value, anterior chamber depth, lens thickness and axial length data were collected and analyzed. RESULTS: This study evaluated the data in 65 eyes of 65 patients who had undergone cataract surgery. The mean age of patients was $59.3 \pm$ 15.71 years. The mean corneal astigmatism was $1.37 \mathrm{D} \pm 1.4 \mathrm{D}$ (range 0.00-6.75D). Corneal astigmatism was higher than $1.00 \mathrm{D}$ in $32.3 \%$ of cases. The mean average keratometry was $44.54 \pm 1.83 \mathrm{D}$. The magnitude of corneal astigmatism was positively correlated with age $(p<0.001)$ and there was a tendency for corneal astigmatism to increase with age above 50 years. Against-the-rule regular astigmatism was the most common type (46.2\%) of astigmatism observed in this study. CONCLUSION: The present report showed the pattern of corneal astigmatism before cataract surgery in the patients at Nepalgunj Medical College Teaching Hospital. One third of cataract patients had corneal astigmatism of more than 1.0D. This finding provide the important normative reference and help ophthalmologists to plan and manage the cost-effective correction of preexisting corneal astigmatism in cataract patients to achieve the best visual outcome.
\end{abstract}

Key words: Biometry, cataract, corneal astigmatism

\section{INTRODUCTION}

Cataract is the leading cause of blindness worldwide. Treatment of advanced cataract is surgery to restore visual function. Extra Capsular Cataract Extraction (ECCE) has three techniques: conventional ECCE, manual small incision cataract surgery and Phacoemulsification. Phacoemulsification is the preferred surgical method for the treatment of cataract worldwide whereas manual Small Incision Cataract Surgery (SICS) is a cost effective alternative in developing nations. Accurate measurement of ocular Axial Length (AL), Keratometry (K) and Anterior Chamber Depth (ACD) before cataract surgery is essential to obtain the precise degree of Intraocular Lens (IOL). Implantation of IOL of accurate power is crucial to achieve satisfactory postoperative refractive and visual outcome for cataract patients $s^{1,2,3}$.

Most previous studies of preoperative ocular biometry and

1. Dr. Bikram Bahadur Thapa

2. Dr. Y. Dhakal

3. Mr. J. K. Verma

4. Dr. P. Manandhar

Address for correspondence:

Dr. Bikram Bahadur Thapa

Department of Ophthalmology

Nepalgunj Medical College \& Teaching Hopsital

Nepalgunj, Banke, Nepal

Email: drbbthapa@gmail.com corneal astigmatism on cataract patients focused on the European, American and Chinese populations $s^{1,5-8,9,10}$. The epidemiological investigation of ocular biometry and corneal astigmatism of cataract patients in Karnali zone, Lumbini zone, Tilganga eye institute and Tribhuwan University teaching hospital Kathmandu of Nepal have been studied ${ }^{10-13}$ but study in Bheri Zone has not been conducted till date. Therefore, the aim of our study was to determine the prevalence of corneal astigmatism and distribution of biometric parameters using the autorefracto keratometry (ARK) and Ultrasound A_B scan before surgery in cataract patients of Bheri zone of Nepal. This study provides some reference for improving cataract surgical procedures and designing an intraocular lens to meet eye characteristics of the population of this zone of Nepal.

\section{MATERIAL AND METHODS}

This study was approved by the institutional review committee of Nepalgunj medical college, Nepal and followed the tenets of the Declaration of Helsinki. Data of cataract patients who underwent surgery at Nepalgunj medical college and teaching Hospital, Nepalgunj between January 2017 and November 2017 was reviewed. All patients who were residents of Bheri zone Nepal and had cataract were included. Patients with history of ocular surgery, such as refractive surgery, corneal diseases, ocular inflammation and trauma; patients from outside Bheri zone were excluded.

Routine eye examinations were performed before surgery 
including visual acuity, retinoscopy, tonometry, slit lamp and dilated fundus evaluation. The procedures were fully explained to each patient and written informed consent was obtained. Biometry examination including Ocular axial length (AL), anterior chamber depth (ACD) and lens thickness [LT] of each cataract affected eye were measured with the ultrasound A_B scan (compact touch Quantel Medical, FRANCE). Keratometry (K) and corneal astigmatism were measured using autorefracto-keratometer (Shin Nippon AccurefK-90 Rexxam Co.Itd, Japan).

The patients were divided into 7 groups on the basis of age as follows: 30 years, 30-40 years, $41-50$ years, $51-60$ years, 61-70 years, $71-80$ years, and $81-90$ years and older. All eyes were stratified into 4 groups based on $\mathrm{AL}$ as follows: shorter than $22.0 \mathrm{~mm}, 22.0-24.5 \mathrm{~mm}, 24.5 \mathrm{~mm}-26.0 \mathrm{~mm}$ and longer than $26.0 \mathrm{~mm}$.

\section{Statistical analysis}

All data were recorded in Microsoft Excel sheet and analyzed using the Kolmogorov-Smirnov test for normal distribution. Continuous variables were expressed as the mean \pm standard deviation for those displaying normal distribution. One-way analysis of variance (ANOVA) and the Kruskal-Wallis test were applied for the comparison of variance for normally and nonnormally distributed data among the different age groups respectively. Statistical analysis was performed using SPSS software (IBM Corporation, Armonk, NY, USA). P-values less than 0.05 were considered statistically significant.

\section{RESULTS}

This study evaluated 65 eyes of 65 cataract patients who were the resident of Bheri zone. The mean age of patient was $59.3 \pm 15.71$ years. The male to female ratio was $1: 1.3$. Most of the patients were of Chhetry, Madheshi, Tharu, Shikh and Muslim races. $40 \%$ had preoperative visual acuity (VA) $<6 / 60$ and $92 \%$ had preoperative $V A$ of $\leq 6 / 24$. The mean axial length was $22.93 \pm 1.34 \mathrm{~mm}$, mean Anterior Chamber depth (ACD) was $2.71 \pm 0.63 \mathrm{~mm}$ and mean Lens Thickness was $3.16 \pm 1.20 \mathrm{~mm}$. The mean average keratometry was $44.54 \pm 1.83 \mathrm{D}$. The mean astigmatism was $1.37 \mathrm{D} \pm 1.4 \mathrm{D}$.

\begin{tabular}{|l|c|c|}
\hline Astigmatism & Number & Percentage \\
\hline$\leq 1 \mathrm{D}$ & 44 & 67.7 \\
\hline $1.01-2 \mathrm{D}$ & 11 & 16.9 \\
\hline $2.01-3.0 \mathrm{D}$ & 4 & 6.2 \\
\hline$>3.0 \mathrm{D}$ & 6 & 9.3 \\
\hline
\end{tabular}

Table I: Frequency of amount of astigmatism

\begin{tabular}{|l|c|c|c|c|c|c|}
\hline Age group (years) & Number & $\begin{array}{c}\text { Astigmatism } \\
\text { (D) }\end{array}$ & $\begin{array}{c}\text { Anterior } \\
\text { chamber depth } \\
(\mathbf{m m})\end{array}$ & $\begin{array}{c}\text { Lens thickness } \\
\text { (mm) }\end{array}$ & $\begin{array}{c}\text { Axial length } \\
\text { (mm) }\end{array}$ & $\begin{array}{c}\text { Average } \\
\text { keratometry (D) }\end{array}$ \\
\hline$\leq 30 \mathrm{yrs}$ & 3 & $2.42 \pm 2.36$ & $0.87 \pm 1.50$ & $0.80 \pm 1.38$ & $23.65 \pm 5.25$ & $43.03 \pm 2.23$ \\
\hline $31-40 \mathrm{yrs}$ & 6 & $0.67 \pm 0.38$ & $2.99 \pm 0.35$ & $4.12 \pm 0.73$ & $23.55 \pm 0.58$ & $43.87 \pm 0.99$ \\
\hline $41-50 \mathrm{yrs}$ & 5 & $1.30 \pm 0.82$ & $2.83 \pm 0.41$ & $2.88 \pm 0.89$ & $23.19 \pm 0.84$ & $44.43 \pm 1.47$ \\
\hline $51-60 \mathrm{yrs}$ & 20 & $1.61 \pm 1.7$ & $2.80 \pm 0.45$ & $3.79 \pm 0.99$ & $22.72 \pm 0.61$ & $44.79 \pm 1.5$ \\
\hline $61-70 \mathrm{yrs}$ & 19 & $1.15 \pm 1.49$ & $2.73 \pm 0.43$ & $3.67 \pm 1.13$ & $22.94 \pm 1.40$ & $44.55 \pm 2.29$ \\
\hline $71-80 \mathrm{yrs}$ & 8 & $1.28 \pm 1.36$ & $2.84 \pm 0.42$ & $4.21 \pm 0.86$ & $22.60 \pm .0 .94$ & $44.84 \pm 2.31$ \\
\hline$>80 \mathrm{yrs}$ & 4 & $1.81 \pm 1.18$ & $2.72 \pm 0.32$ & $3.65 \pm 1.35$ & $22.71 \pm 0.46$ & $44.93 \pm 1.09$ \\
\hline Total & 65 & $1.37 \pm 1.46$ & $2.71 \pm 0.63$ & $3.62 \pm 1.20$ & $22.92 \pm 1.34$ & $44.54 \pm 1.83$ \\
\hline
\end{tabular}

Table II: Age wise distribution of biometric parameter

\begin{tabular}{|l|c|c|c|c|c|}
\hline Axial length & Number & Astigmatism (D) & $\begin{array}{c}\text { Average } \\
\text { keratometry(D) }\end{array}$ & ACD(mm) & LT(mm) \\
\hline$<22.00 \mathrm{~mm}$ & 10 & $0.73 \pm 0.54$ & $46.60 \pm 1.46$ & $2.14 \pm 0.81$ & $3.20 \pm 1.67$ \\
\hline $22.0-24.5 \mathrm{~mm}$ & 48 & $1.49 \pm 1.56$ & $44.44 \pm 1.40$ & $2.78 \pm 0.54$ & $3.65 \pm 1.10$ \\
\hline $24.51-26 \mathrm{~mm}$ & 6 & $0.96 \pm 0.51$ & $42.60 \pm 2.05$ & $3.1167 \pm 0.47$ & $4.2783 \pm 0.96$ \\
\hline$>26 \mathrm{~mm}$ & 1 & $4.75 \pm 0.0$ & $40.47 \pm 0.0$ & $2.60 \pm 0.0$ & $2.39 \pm 0.0$ \\
\hline Total & 65 & $1.37 \pm 1.46$ & $44.54 \pm 1.83$ & $2.71 \pm 0.63$ & $3.62 \pm 1.20$ \\
\hline
\end{tabular}

Table III: Distribution of parameter for different axial length

\begin{tabular}{|l|c|c|c|c|c|c|}
\hline Gender & Number & Astigmatism & K & ACD & LT & AL \\
\hline Female & 37 & $1.37 \pm 1.49$ & $44.72 \pm 1.87$ & $2.65 \pm 0.61$ & $3.46 \pm 1.28$ & $22.56 \pm 1.19$ \\
\hline Male & 28 & $1.38 \pm 1.45$ & $44.31 \pm 1.79$ & $2.79 \pm 0.65$ & $3.83 \pm 1.09$ & $23.41 \pm 1.40$ \\
\hline Total & 65 & $1.37 \pm 1.46$ & $44.54 \pm 1.83$ & $2.71 \pm 0.63$ & $3.62 \pm 1.20$ & $22.92 \pm 1.34$ \\
\hline
\end{tabular}

Table IV: Gender wise distribution of biometric parameter 
The bar diagram of the frequency distribution of corneal astigmatism for all patients are shown in Figure 1. Corneal astigmatism of $\leq 1.00 \mathrm{D}$ was the most common of range values (67.4\%), followed by 1.01-2D (16.9\%), 2.01-3.0 D (6.2\%) and > $3 \mathrm{D}(9.3 \%)$.

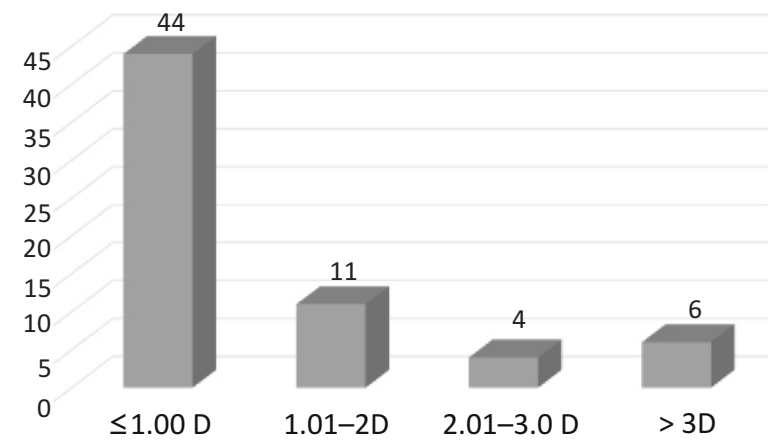

Table I: Frequency of amount of astigmatism

The age wise distribution of biometric parameter is shown in Table II. The keratometry values gradually increased with age. Most patients in this study were between 51 and 60 years old (30.77\%) followed by 61 and 70 years old (29.23\%).The AL and ACD values showed a gradually decreasing trend with age; whereas lens thickness showed gradually increasing trend with age and corneal astigmatism showed first a decline and then a rising trend.

Table III shows the distribution of ocular biometry for different ALs. The AL in the majority of eyes was between 22.0 and 24.5 $\mathrm{mm}$ (73.85\%). The mean $A C D$ and $L T$ increases as the $A L$ increases $(P<0.007)$. Whereas keratometry values $(K)$ decreases with an increase in AL. The smallest mean corneal astigmatism (0.73D) was in eyes with an AL of less than 22.0 $\mathrm{mm}$, and the largest (4.75D) was in eye with a longer AL than $26.0 \mathrm{~mm}$. Gender wise distribution of biometric parameter is tabulated in this table IV. It is found that male longer but less steeper eye than female.

Corneal astigmatism was with-the-rule (WTR, the steepest meridian of the cornea being within $90 \pm 30$ degrees) in 24 eyes
(36.9\%), against-the-rule (ATR, the steepest meridian of the cornea being within $180 \pm 30$ degrees) in 30 eyes $(46.2 \%)$ and oblique (steepest meridian between 30 and 60 degrees or 120 and 150 degrees) in 11 eyes (16.9\%). The ATR astigmatism was the most common type as shown in table $\mathrm{V}$.

\begin{tabular}{|l|c|c|}
\hline Type & Number & Percent \\
\hline WTR & 24 & 36.9 \\
\hline ATR & 30 & 46.2 \\
\hline OA & 11 & 16.9 \\
\hline Total & 65 & 100 \\
\hline
\end{tabular}

Table V: Distribution of type corneal astigmatism

\section{DISCUSSION}

The cornea and lens are the main contributors to ocular astigmatism. For patients undergoing uncomplicated cataract surgery, significant preoperative corneal astigmatism remains the major obstacle to obtain satisfactory postoperative visual outcome as the surgery eliminate lenticular astigmatism. This presumes that surgically induced astigmatism has been minimized. The preoperative corneal stigmatism is often overlooked and this leads to patient dissatisfaction.

Prevalence and type of preoperative corneal astigmatism in patients with cataract has been reported from several countries and has been taken into account during Surgery ${ }^{1,7,9,14,15}$. Bheri zone of Nepal has huge burden of cataract with number of cataract surgery increasing each year but this type of study has not been documented from this zone of Nepal till date. So, we compared the results of present study with the study from various regions of Nepal as well as of other countries in table no $\mathrm{VI}^{10-13}$.

It is found that the corneal power in patients from Bheri zone of Nepal was greater than that in other different regions of Nepal and other countries ${ }^{10-13}$. The axial length of people of Bheri, Karnali, Bagmati zone of Nepal and Vietnam were comparable whereas Chinese eyes were longer than other studies ${ }^{1,10-13,15}$. The highest corneal astigmatism in our study was $6.75 \mathrm{D}$ as seen in the Chinese studies. ${ }^{1}$. The $67.7 \%$ of cataract patients has

\begin{tabular}{|l|l|c|c|c|c|c|c|}
\hline S.N & Study Sample & Size & $\begin{array}{c}\text { Age } \\
\text { Range }\end{array}$ & $\begin{array}{c}\text { Age } \\
\text { Mean } \pm \text { SD }\end{array}$ & $\begin{array}{c}\text { IOL } \\
\text { formula }\end{array}$ & $\begin{array}{c}\text { K } \\
\text { Mean } \pm \text { SD }\end{array}$ & AL Mean \pm SD \\
\hline 1. & Bheri, Nepal & 65 & $1-90$ & $59.3 \pm 15.71$ & SRK II & $44.54 \pm 1.83$ & $22.92 \pm 1.34$ \\
\hline 2. & Karnali, Nepal & 1055 & $8-98$ & $64.34 \pm 11.25$ & SRK II & $44.11 \pm 1.6$ & $22.68 \pm 0.88$ \\
\hline 3. & $\begin{array}{l}\text { Tilganga, } \\
\text { Nepal }\end{array}$ & 5109 & $2-111$ & $61.93 \pm 16.48$ & SRK II & $43.69 \pm 1.8$ & $23.08 \pm 1.26$ \\
\hline 4. & Central China & 3209 & $32-95$ & $70.51 \pm 9.81$ & NR & $44.29 \pm 1.58$ & $24.38 \pm .47$ \\
\hline 5. & Vietnam & 346 & $19-87$ & $64.11 \pm 13.58$ & SRK T & $44.24 \pm 1.53$ & $22.96 \pm 0.99$ \\
\hline
\end{tabular}

Table VI: Comparison of corneal astigmatism and biometric parameters 
astigmatism lesser than $1.00 \mathrm{D}$ in this study similar to that of Chaudhary et $\mathrm{al}^{13}$ and $\mathrm{Yu}$ et $\mathrm{al}^{1}$. In our study the Corneal astigmatism across all age groups showed a similar distribution pattern compared to various previous studies ${ }^{5,7,8}$. In our study vast majority of eyes with cataract had a corneal astigmatism between $0.0 \mathrm{D}$ and $1.0 \mathrm{D}$. In contrast, only a small percentage of eyes with corneal astigmatism greater than $3.0 \mathrm{D}$ were observed. The astigmatism is higher in extreme of ages. It has linear rise from the age of 30 years similar to the findings of previous studies ${ }^{1,10-13}$. Understanding the distribution of astigmatism is important to help ophthalmologists choose first-line treatment that will be most effective and reduce the occurrence of postoperative astigmatism. This includes procedures such as limbal relaxing incisions ${ }^{16}$, opposite clear corneal incisions ${ }^{17}$, excimer laser refractive procedures ${ }^{18,19}$, femto second laser-assisted astigmatic keratotomy ${ }^{19}$ and toric IOL implantation ${ }^{20-23}$. At present, toric IOL implantation is highly recognized and it can be used to correct up to $8.0 \mathrm{D}$ of corneal astigmatism after cataract surgery ${ }^{24,25}$ In this study, $32.7 \%$ of cataract patients in Bheri zone had corneal astigmatism values more than $1.0 \mathrm{D}$, most of which could be effectively corrected with toric IOLs implantation during cataract surgery. Therefore, the use of toric IOLs in Bheri zone is still required for a group of people who are affording the cost and demanding the best outcome.

The mean $A L$ in the present study is consistent with that reported by Baral et $\mathrm{al}^{10}$, Murchison et $\mathrm{al}^{12}$ and Nauze et $\mathrm{al}^{15}$ but found to have shorter axial length than the report from Chinese population ${ }^{1}$. The AL and ACD values gradually decreased with age; LT gradually increased with age whereas corneal astigmatism showed an initial decline and then subsequently an increase. This suggests that the human eye biometric parameters change with age. This might be related to the occurrence of lens opacity and thickening, accommodative lags, cornea arcus senilis, extra ocular muscle relaxation and orbital fat prolapsed generating compression on the eye ${ }^{1}$.

Ocular axial length affects other components of the biometric parameters in eyes. In the present study, we found that as the AL increases, ACD and LT also increases but this relation doesn't hold true for $>26 \mathrm{~mm}$ long eyes. Additionally, the keratometry values (K) decreased when the AL increases. These results are consistent with the findings of previous studies ${ }^{1,5,26}$. This suggests that the cornea becomes flatter when the AL increases. ATR astigmatism accounted for the majority of the cataract population and the prevalence increased with age. By contrast, the percentage of WTR astigmatism decreased with age. These findings are consistent with the characteristics seen in populations in the previous studies ${ }^{5,8,27}$. These changes have been found to be due to a discrepancy in eyelid morphology ${ }^{28}$.

Autorefractokeratometer is unable to reflect the entire corneal surface curvature. Corneal topography can measure the total corneal astigmatism, and is more accurate for distinguishing between regular and irregular astigmatism. Total corneal astigmatism is determined by topography which is the major factor affecting postoperative visual quality; therefore it is crucial to select a reasonable and economical operative procedure to correct corneal astigmatism ${ }^{1}$.

The most cost-effective methods to reduce corneal astigmatism are to make smaller and appropriately located incision during surgery. Our study reported that against the rule (ATR) astigmatism accounted for the majority of the cataract population and that prevalence increased with age. Thus, our study suggests that when considering large-scale cataract surgery for patients with a low socioeconomic status in this Zone, smaller and temporal incisions should be used frequently to reduce preexisting corneal astigmatism.

Our study has some limitations. First, the ocular biometric data drawn from cataract patients in our hospital do not completely represent the data of the whole population in Bheri Zone of Nepal. Second, the sample size of our study is small.

\section{CONCLUSIONS}

Our study determined the distribution of ocular biometric parameters and the characteristics of corneal astigmatism as well as their variation among different age groups in Bheri zone. The profile of ocular biometric data and corneal astigmatism may help Ophthalmologists improve their surgical procedures including appropriate IOL choice and accurate placement of incision to have good postoperative visual outcome in people of this region.

\section{REFERENCES}

1. Yu J, Zhong J, Mei Z, Zhao F, Tao N and Xiang Y. Evaluation of biometry and corneal astigmatism in cataract surgery patients from Central China.BMC Ophthalmology2017;17:56 DOI 10.1186/s12886-017-0450-2.

2. Ruit $S$, Gurung $R$, and Vyas $S$. The role of small incision suture-less cataract surgery in the developed world. Curr Opin Ophthalmol 2018; 29:105-109.

3. Olsen T. Improved accuracy of intraocular lens power calculation with the Zeiss IOL Master. Acta Ophthalmol Scand. 2007;85:84-7.

4. Fotedar R, Wang JJ, Burlutsky G, Morgan IG, Rose K, Wong TY, et al. Distribution of axial length and ocular biometry measured using partial coherence laser interferometry (IOL master) in an older white population. Ophthalmology.2010; 117:417-23.

5. Hoffmann PC, Hutz WW. Analysis of biometry and prevalence data for corneal astigmatism in 23,239 eyes. J Cataract Refract Surg. 2010; 36: 1479-85.

6. De Bernardo M, Zeppa L, Cennamo M, laccarino S, Rosa N. Prevalence of corneal astigmatism before cataract surgery in Caucasian patients. Eur J Ophthalmol. 2014;24: 494-500.

7. Khan MI, Muhtaseb M. Prevalence of corneal astigmatism in patients having routine cataract surgery at a teaching hospital in the United Kingdom. J Cataract Refract Surg. 2011;37:1751-5.

8. Yuan X, Song H, Peng G, Hua X, Tang X. Prevalence of corneal astigmatism in patients before cataract surgery in Northern China. J Ophthalmol. 2014; 2014:536412. 
9. Guan Z, Yuan F, Yuan YZ, Niu WR. Analysis of corneal astigmatism in cataract surgery candidates at a teaching hospital in shanghai. China J Cataract Refract Surg. 2012;38: 1970-7.

10. Baral P, Baral N, Maharjan I.M.,Gautam B. R., Bhandari M. Biometric parameters and intra ocular lens power Nepal J Ophthalmol 2014; 6: 192-196.

11. SherchanA, KandeIR P, SharmaMK, SapkotaYD, AghajanianJ, Bassett K L. Blindness prevalence and cataract surgical coverage in Lumbini Zone and Chitwan District of Nepal. $\mathrm{Br} \mathrm{J}$ Ophthalmol2010; 94:161-166.

12. Murchison A, Richards M, Tabin G, Ruit S, Gurung R.Optimal single intraocular lens power for the Nepali population. Br J Ophthalmol.2004; 88:1235-1236.

13. Chaudhary M, Dahal HN. Prevalence and types of corneal astigmatism in patients undergoing cataract surgery. Journal of Institute of Medicine, April, 2017, 39:,22-28.

14. Chen W, Zuo C, Chen C, Su J, Luo L, Congdon N, et al. Prevalence of corneal astigmatism before cataract surgery in Chinese patients. J Cataract Refract Surg. 2013;39:188-92.

15. NauzeJ L,Thanh TK, Lap TD et al. Intraocular lens power prediction in a Vietnamese population. Ophthalmic Epidemiol1999;6(3):147-158.

16. Ouchi M, Kinoshita S. AcrySof IQ toric IOL implantation combined with limbal relaxing incision during cataract surgery for eyes with astigmatism >2.50 D. J Refract Surg. 2011;27:643-7.

17. Mendicute J, Irigoyen C, Ruiz M, Illarramendi I, Ferrer-Blasco T, Montes-Mico R. Toric intraocular lens versus opposite clear corneal incisions to correct astigmatism in eyes having cataract surgery. J Cataract Refract Surg. 2009;35: 451-8.

18. Gunvant P, Ablamowicz A, Gollamudi S. Predicting the necessity of LASIK enhancement after cataract surgery in patients with multifocal IOL implantation. Clin Ophthalmol. 2011;5:1281-5.

19. Norouzi $\mathrm{H}$, Rahmati-Kamel M. Laser in situ keratomileusis for correction of induced astigmatism from cataract surgery. J Refract Surg. 2003;19:416-24.

20. RuckI T, Dexl AK, Bachernegg A, ReischI V, Riha W, Ruckhofer J, et al. Femtosecond laser-assisted intrastromal arcuate keratotomy to reduce corneal astigmatism. J Cataract Refract Surg. 2013;39:528-38.

21. Horn JD. Status of toric intraocular lenses. Curr Opin Ophthalmol. 2007;18:58-61.

22. Bachernegg A, RuckI T, Riha W, Grabner G, Dexl AK. Rotational stability and visual outcome after implantation of a new toric intraocular lens for the correction of corneal astigmatism during cataract surgery. J Cataract Refract Surg. 2013;39: 1390-8.

23. Bachernegg A, Ruckl T, Strohmaier C, Jell G, Grabner G, Dexl AK. Vector analysis, rotational stability, and visual outcome after implantation of a new aspheric Toric IOL. J Refract Surg. 2015;31: 513-20.

24. Ferreira TB, Berendschot TT, Ribeiro FJ. Clinical outcomes after cataract surgery with a new transitional toric intraocular lens. J Refract Surg. 2016; 32: 452-9.

25. Rubenstein JB, Raciti M. Approaches to corneal astigmatism in cataract surgery. Curr Opin Ophthalmol. 2013;24:30-4.

26. Jivrajka R, Shammas MC, Boenzi T, Swearingen M, Shammas HJ. Variability of axial length, anterior chamber depth, and lens thickness in the cataractous eye. J Cataract Refract Surg. 2008;34: 289-94.

27. Nemeth G, Szalai E, Berta A, Modis L Jr. Astigmatism prevalence and biometric analysis in normal population. Eur J Ophthalmol. 2013;23:779-83
28. Read SA, Collins MJ, Carney LG. A review of astigmatism and its possible genesis. Clin Exp Optom. 2007;90: 5-19. 